УДК 331.104

\title{
ТРУДОВОЙ ПОТЕНЦИАЛ И УПРАВЛЕНИЕ ТРУДОМ В ТЕКСТИЛЬНОЙ И ШВЕЙНОЙ ПРОМЫШЛЕННОСТИ КАК ОБЪЕКТЫ ЭКОНОМИЧЕСКОГО ИССЛЕДОВАНИЯ
}

\author{
Т.В. СЕРГИЕВИЧ \\ аспирант кафедры «Экономика и право»
}

Белорусского национального технического университета, г. Минск

Аннотация

На основании рассмотренных в статье ключевых подходов $\kappa$ категории «трудовой потенциил» и основных направлений исследования управления трудом даны определения понятий «трудовой потенцииал текстильной и швейной промышленности», «управление трудом в текстильной и швейной промыиленности». Выделены основные риски для отрасли и факторы, обуславливающие ее экономический рост.

Ключевые слова: трудовой потенцииал, управление трудом, текстильная и швейная промышленность, человеческий капитал, экономический рост, инновации, легкая промыиленность.

\section{Abstract}

The key approaches to the category of "labor potential" and the main directions of labor management researches are given in the article. On this basis there were given definitions of "labor potential of the textile and clothing industry", "management of labor in the textile and clothing industry." The basic risks for the industry and the factors contributing to its economic growth were marked out.

Keywords: labor potential, labor management, textile and garment industry, human capital, economic growth, innovation, light industry.

\section{ВВЕДЕНИЕ}

Усиление гносеологического интереса к проблеме трудовых отношений в последнее время обусловлено распространением гипотезы о доминировании трудовых отношений в системе детерминации социально-классовой структуры общества [1, с. 2]. Стремительные изменения внешней среды социально-экономических систем, трансформации их внутренних структур, нарастающее давление практики управления, обусловленное несоответствием ей устоявшихся подходов к управлению трудом, требуют поиска новых решений старых задач, таких 
как повышение производительности труда, формирование мотивационной системы субъектов управления трудом, эффективное использование трудового потенциала, оптимизация структуры занятости.

\section{РЕЗУЛЬТАТЫ И ИХ ОБСУЖДЕНИЕ}

Исследованию категории «трудовой потенциал» посвящены работы таких авторов, как К.Х. Абдурахманов [2], В.С. Буланов [3], И.С. Волохин [4], Л.С. Дегтярь [5], Л. Кунельский [6], В. Костаков [7], Э.А. Лутохина [8], И.С. Маслова [9], А.П. Морова [10], Ю.Г. Одегов [11], Я.А. Павлов [12], А. Попов [7], Х.М. Психомахов [13], Г.П. Сергеева [14], Л.С. Чижова [14], Н.Р. Хадасевич [15], Н.И. Шаталова [16], С.В. Шевченко [17], П.Э. Шлендер [18]. Анализ научных публикаций по этой теме показал, что до настоящего времени в экономической теории не выработано единого взгляда на трудовой потенциал и его место в системе экономических категорий. Вместе с тем эта категория все чаще попадает в поле зрения ученых экономистов, что связано в первую очередь со становлением кибернетики (позже - синергетики), методология которой используется при исследовании сложных социальноэкономических систем, в том числе в управлении названными системами, ключевой фигурой которых является человек.

Категория «трудовой потенциал» не является принципиально новой в экономической науке - в советской литературе она активно использовалась с 80-х г. ХХ в. В этот период термин употреблялся преимущественно в значении, близком по содержанию к понятию «трудовые ресурсы», а иногда как его синоним, что стало основанием для формирования первого (отождествляющего) подхода к пониманию этого социально-экономического явления. Представителями отождествляющего подхода являются И.С. Волохин [4], Л.С. Дегтярь [5], В. Костаков [7], Л. Кунельский [6], А. Попов [7], Г.П. Сергеева [14], Л.С. Чижова [14]. Они рассматривают трудовой потенциал как совокупность количественных и качественных характеристик трудовых ресурсов. Это явилось следствием преобладания синкретичных взглядов на систему трудовых отношений и трудовой потенциал, порождаемом относительно непродолжительным периодом изучения этого явления, упрощенной трактовкой экономической системы общества СССР. Г.П. Сергеева и Л.С. Чижова, например, определяют трудовой потенциал как «ресурсы труда, которыми располагает общество. Численность трудоспособного населения и его качественные характеристики (пол, возраст, образование, профессиональная подготовка, квалификация и т.д.), - отмечают они, определяют реальное значение трудового потенциала» $[14$, с. 3]. По мнению В. Костакова и А. Попова, количественные и качественные 
показатели должны быть рассмотрены комплексно: «трудовой потенциал страны и ее регионов - это соответствующие трудовые ресурсы, рассматриваемые в аспекте единства их количественной и качественной стороны» [7, с. 61]. Развивая эту посылку, И.С. Волохин определил трудовой потенциал как «совокупность ресурсов труда, состоящих из множества взаимосвязанных элементов. Основными признаками, служащими основанием для отнесения того или иного элемента к данной совокупности, являются физические или интеллектуальные способности к труду, которыми обладает организм, живая личность» [4, с. 91]. Выделение трудоспособности как единственного критерия отнесения того или иного элемента к системе свидетельствует об отождествлении трудового потенциала и трудовых ресурсов, которое, с одной стороны, делает возможной методику его оценки, а с другой - снижает гносеологическую значимость полученных результатов. Заслугой представителей отождествляющего подхода стало введение категории «трудовой потенциал» в научный оборот. Количественная и качественная составляющая трудовых ресурсов послужила отправным пунктом в исследовании категории «трудовой потенциал»; в характеристике трудового потенциала и сегодня сложно уйти от количественных показателей наличных трудовых ресурсов, от оценки их квалификации, инновационной активности и т.д. Вместе с тем в виду сложности объекта невозможно ограничиться обобщенными статистическими данными для оценки трудового потенциала.

Развитием отождествляющего подхода к пониманию трудового потенциала стал потенциально-детерминированный подход, возникший как реакция на задачу по достижению роста производительности труда. Представителями потенциально-детерминированного подхода являются В.С. Буланов [3], Э.А. Лутохина [8], И.С. Маслова [9], Н.Р. Хадасевич [15], Н.И. Шаталова [16], П.Э. Шлендер [18]. Ими заложены теоретикометодологические основы исследования трудового потенциала и его оценки. При потенциально-детерминированном подходе трудовой потенциал представляет собой меру явных и скрытых возможностей трудовых ресурсов по применению трудоспособности. П.Э. Шлендер, например, рассматривает трудовой потенциал предприятия как «предельную величину возможного участия работников в производстве с учетом их психофизиологических особенностей, уровня профессиональных знаний, накопленного опыта при наличии

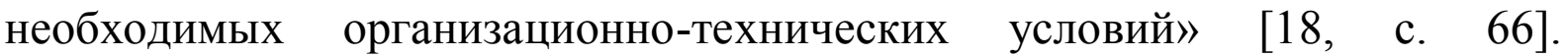
Э.А. Лутохина развивает представление о категории «трудовой потенциал», адаптируя его к условиях современной экономики. Ученый подчеркивает несоответствие традиционного содержания понятия 
«рабочая сила» новым реалиям, что обуславливает актуальность применения понятия «"личностный трудовой потенцииал", которое должно отразить субстанциональную основу нового, современного рынка труда» [8, с. 13]. Э.А. Лутохина определяет личностный трудовой потенциал как «совокупность личностных возобновляемых и развиваемых, явных и неявных способностей и качеств данного индивида, которые определяют потенциальную меру трудовой активности личности» [8, c. 13]. Представители потенциально-детерминированного подхода существенно расширили содержание трудового потенциала. Они первыми выделили блок скрытых возможностей трудовых ресурсов, которые могут быть выявлены и реализованы. Вместе с тем недостаточно внимания было уделено факторам, от которых зависит реализация этих возможностей.

На последний вопрос отвечают представители факторноситуационного подхода, а именно К.Х. Абдурахманов [2], Ю.Г. Одегов [11], Я.А. Павлов [12], Х.М. Психомахов [13], С.В. Шевченко [17]. Этот подход выявляет зависимость реального трудового потенциала от организационно-технических условий труда, которые длительное время в исследованиях трудового потенциала не учитывались. С.В. Шевченко отмечает по этому поводу, что «сегодня при оценке эффективности использования трудового потенциала работающих основной акцент приходится делать <..> на анализе социально-экономических условий, в которых он реализуется и от которых зависит результативность труда работающих» $[17$, с. 26]. По мнению Ю.Г. Одегова, трудовой потенциал это «персонифицированная (воплощенная в конкретных личностях) рабочая сила, взятая в совокупности своих качественных характеристик, как реализованных, так и еще не реализованных в определенных организационно-технических и социально-экономических условиях производства» [11, с. 11-12]. Возможности работников по их участию в труде зависят не только от самих работников и их совокупных характеристик, но от того, какие производственные условия им будут обеспечены. В качестве интегрального измерителя этих возможностей и условий представители факторно-ситуационного подхода используют производительность труда $[11$, с. 12; 13, с. 9]. Комплексный учет условий, в которых реализуется трудовой потенциал, позволяет использовать это социально-экономическое явление в целях системного анализа состояния и динамики экономических процессов для составления прогнозов и принятия обоснованных управленческих решений. Вместе с тем использование такого показателя, как производительность труда, традиционно рассчитываемого как отношение ВВП к численности занятых в экономике, не позволяет оценить трудовой потенциал. Это обусловлено неэффективностью статистического показателя производительности труда и упрощением его содержания (подробнее [19]). Факторно-ситуационный 
подход не позволяет провесит разграничение трудового и производственного потенциала.

Рассмотрение трудового потенциала на уровне отдельно взятого индивида не позволяет в полной мере раскрыть сущность этой экономической категории. Эффект коллективного труда обеспечивает накопленный на уровне предприятия, отрасли, кластера и т.д. социальный капитал, уровень которого влияет на величину трудового потенциала. Уровень социального капитала на предприятии сложно вычислить, однако его роль в эффективном труде архиважна. Эта эффективность в общем плане достигается за счет того, что «особенностью социального капитала является то, что он способствует более производительному использованию всех других видов капитала» [20, с. 36] через снижение уровня трансакционных издержек, рост доверия, ускорение и упрощение передачи информации. Это обуславливает рассмотрение трудового потенциала на уровне отрасли. Решение многих проблем более эффективно на уровне государства или отрасли, чем на уровне отдельных предприятий с учетом того, что сегодня в белорусской экономике «возрастает, по сравнению с непереходными системами, роль государства в управлении социальными, экономическими и технико-технологическими процессами в обществе» $[21$, c. 446]. Под текстильной и швейной отраслью промышленности в дальнейшем будем понимать социально-экономический комплекс, в пределах которого осуществляется потребление материальных, трудовых, финансовых и иных хозяйственных ресурсов в целях производства и распределения текстильных изделий и одежды, основным функциональным назначением которого является удовлетворение нужд народного хозяйства и потребностей населения.

Необходимость трансформации существующей системы управления и ее адаптации к современным условиям хозяйствования обусловлена стабилизацией в области промышленной политики; слабые игроки рынка не могут постоянно рассчитывать на меры государственной поддержки; рыночные условия хозяйствования предполагают расчет на собственные источники инвестиций и инноваций. За период существования суверенной Беларуси государству удалось создать благоприятные условия для развития белорусского производства, поддерживающие отечественного производителя, что привело к формированию рентоориентированного поведения у многих крупных предприятий. Сегодня между белорусскими хозяйствующими субъектами в текстильной и швейной промышленности главным объектом конкуренции за факторы производства являются не каналы снабжения сырьем, материалами, инвестиционными и трудовыми ресурсами, а персонификация, размеры, формы, величина государственной поддержки и доступ к административному ресурсу. 
Это является результатом неадаптированности предприятий текстильной и швейной промышленности к рыночным условиям хозяйствования; неразвитости мотивационных механизмов к эффективному труду; отсутствия стратегического планирования на предприятиях отрасли на основе выделения своих конкурентных преимуществ.

Долговременное сохранение низкого уровня заработной платы в отрасли вызвало ухудшение качества человеческого капитала в текстильной и швейной промышленности, что выступает главным ограничителем модернизации отрасли и достижения среднеевропейского уровня по созданию добавленной стоимости, в то время как его расширенное воспроизводство является условием необходимой модернизации. Это выступает одновременно и причиной, и следствием снижения конкурентоспособности предприятий отрасли на рынке труда. Эти и некоторые другие специфичные особенности приводят к тому, что рынок труда отрасли становится во многом закрытым, что приводит к обмену между предприятиями трудовыми ресурсами низкого качества, в то время как должен способствовать к постоянной конкуренции за получение рабочей силы лучшего качества. Указанные противоречия и неэффективность практики управления обуславливают актуальность исследования специфики управления трудом в текстильной и швейной промышленности. $\mathrm{C}$ учетом этих особенностей под трудовым потенциалом текстильной и швейной промышленности будем понимать производственные, инновационные, адаптационные и воспроизводственные возможности трудовых ресурсов текстильной и швейной промышленности, управление которыми осуществляется с использованием мотивационных и административно-командных механизмов. Воспроизводственные возможности трудовых ресурсов определяются привлекательностью предприятий отрасли как работодателей, степенью открытости внутренних рынков труда, качеством человеческого капитала занятых и потенциально занятых в отрасли.

Первым подходом к исследованию управления трудом стал моноцентрический подход, представителями которого являются Е.Г. Антосенков [22], Л.С. Бляхман [23], А.И. Волгин [24], В.П. Локтев [25], Г.Р. Погосян [26], Ф. Тейлор [27], Ф. Херцберг [28], Е.И. Хрищев [23]. Формирование науки управления по существу происходило в рамках моноцентрического подхода, возникшего как реакция на недостатки в практике. Этот подход характеризуется целостностью объекта исследования, являющегося элементом систем управления трудом. Повышение производительности труда достигается путем совершенствования одного, наиболее влиятельного по мнению того или иного автора фактора. Ф. Тейлор, например, основной проблемой в промышленности считал медлительность людей в работе. Он предложил 
внедрить систему научного управления, которая включала в себя изучение способа соединения работников со средствами производства, разработку наиболее эффективного алгоритма работ (главный критерий эффективности - скорость выполнения операции), и самый важный этап «обучение и развитие каждого отдельного работника в предприятии для того, чтобы он мог <..> давать труд наивысшего качества и притом тот, к которому он наиболее способен по своим естественным склонностям» [27, с. 11]. В 50-х гг. XX в. ученые сосредоточились на разработке новой системы мотивации, отличной от традиционной экономической. Как отмечает Ф. Херцберг, «в области промышленных отношений стало почти аксиомой, что знание, что работнику нужно от своей работы, - необходимое условие качественной работы с персоналом» $[28$, с. 178]. В отечественной науке во второй половине XX в. особое внимание в управлении социально-экономическими системами было уделено применению экономических рычагов управления и, позднее, борьбе со структурной безработицей. Сторонникам моноцентрического подхода удалось подробно изучить отдельные составляющие системы управления трудом, создать теоретико-методологическую базу для дальнейших исследований. Вместе с тем закономерности в том виде, в котором они были выявлены, проявляются в исключительных социальных, цивилизационных, исторических и других условиях, характерных для описываемого периода времени. Действие экономических законов, определяющих эффективность применяемых методов управления, обусловлено, в первую очередь, динамичными интересами людей. Поэтому выводы, сделанные в исследованиях, отнесенных к моноцентрическому подходу, теряют свою актуальность по мере изменения этих факторов.

Излишняя специализация помешала представителям моноцентрического подхода взглянуть на проблему управления трудом комплексно, что стало основой формирования внутренне-детерминационного подхода. Его представителями являются В.В. Адамчук [29], А.В. Батурин [30], Б.Г. Збышко [31], А.Я. Кибанов [32], Л.А. Костин [30], В.Т. Стрейко [31], Б.М. Сухаревский [30], А.И. Рофе [31], которые рассматривают управление трудом как систему. Особенностями внутренне-детерминационного подхода являются рассмотрение управления трудом без учета действия конкретных внешних факторов, попытка полностью охватить структуру системы путем ее детализации и анализа выделенных компонентов. Так, например, А.Я. Кибанов в системе управления трудом в рамках предприятия (для ее обозначения он использует «управление персоналом») выделяет такие подсистемы как «подсистема планирования и маркетинга персонала»; «подсистема найма и учета персонала»; «подсистема условий труда»; «подсистема трудовых отношений»; «подсистема развития 
персонала»; «подсистема мотивации и стимулирования персонала»; «подсистема социального развития»; «подсистема оргструктур управления»; «подсистема правового обеспечения системы управления персоналом»; «подсистема информационного обеспечения системы управления персоналом» [32, с. 31]. Заслугой представителей внутреннедетерминационного подхода стало то, что они первыми применили системный подход к исследованию управления трудом, представив его своих трудах как относительно самостоятельную систему, которая развивается в том числе по своим особым принципам, которые не всегда совпадают с законами развития управления вообще. Вместе с тем представители этого подхода преувеличили автономность этой системы и ее целей. При таком подходе, как правило, при наличии полной детерминации структуры системы управления трудом невозможно определить удельный вес отдельных компонентов системы в обеспечении ее эффективного функционирования.

Эта пробел был восполнен представителями эклектичного подхода, базирующегося на выделении более значимых по мнению отдельных авторов факторов в зависимости от конкретных социально-экономических условий. Представители данного подхода, а именно М.А. Винокуров [33], В.И. Корнеску [34], Г. Саймон [35], Д. Смитбург [35], С.И. Сотникова [36], В. Томпсон [35] рассматривают не всю систему комплексно, а функционирование ее отдельных элементов в тесной связи с внешней средой через детализацию объекта исследования. Представители эклектичного подхода рассматривают управление трудом в конкретном срезе общественных отношений. М.А. Винокуров, например, среди основных факторов, влияющих на управление трудом, выделяет переход к инновационной экономике и экономический кризис [33, с. 6-7]. Эклектичный подход позволил выявить и диагностировать отдельные проблемы, существующие в практике управления. В рамках эклектичного подхода его сторонникам удалось показать сложность и многогранность рассматриваемых систем, выявить, насколько они интегрированы во внешнюю по отношению к управлению трудом среду. Вместе с тем выделение особо значимых по мнению того или иного автора факторов привело к излишней специализации науки управления, которая способна привести к ограниченному представлению о системе в целом. Системный подход предполагает «взвешивание и комплексный учет всех основных факторов, их качественных и количественных характеристик» [37, с. 3], что говорит о невозможности познания всей системы и закономерностей ее развития на основе анализа отдельных элементов и попытке представить систему как простую совокупность этих элементов.

Четвертый (менеджериальный) подход к рассмотрению управления трудом возник как реакция на специализацию исследований 
управления трудом. Его представители, а именно Б.Е. Беккер [38], Р.У. Битти [38], П.Г. Гербст [39], Р. Джонсон [40], Ф. Каст [40], Д. Коул [41], А.В. Молодчик [42], Р.У. Монди [43], Р.М. Ноу [43], Ш.Р. Премо [43], Д. Розенцвейг [40], М.А. Хьюзлид [38], взглянули на систему управления трудом как на компонент системы управления вообще. Посылкой такой точки зрения стала фактическая корректировка стратегий крупных хозяйствующих субъектов в сторону формирования единого целеполагания внутри всего предприятия вне зависимости от конкретных функциональных особенностей отдельных подразделений. Особенностью этого подхода является намеренный отказ от дробления объекта исследования - управления трудом. Сторонники менеджериального подхода считают, что управление трудом как функциональный блок в современной организации нельзя рассматривать обособленно, субъектами управления могут быть не только работники специализированного отдела. Значительно расширяется функциональная составляющая менеджера по кадрам, который сегодня «помогает осуществлять стратегию фирмы, активно участвует в разработке структуры фирмы, является главным носителем и распространителем предпринимательской культуры» [42, с. 176]. М.А. Хьюзлид, Б.Е. Беккер, Р.У. Битти отмечают, что «ответственность за практический успех рабочей силы все чаще возлагается на линейных менеджеров, которые в любой форме выполняют большую часть работы по управлению рабочей силой» [38, с. 35]. Представители менеджериального подхода развивают концепцию приверженности персонала целям предприятия. Рассматривая организацию как систему, а управление трудом - как ее подсистему, они приходят к выводу, что цели этих двух систем должны совпадать. Сторонники менеджериального подхода первыми восприняли изменения в парадигме управления, понимая необходимость отношения к работникам как к ценному ресурсу, эффективность действия которого обеспечивает успех организации. Однако в качестве решения выявленного противоречия ими предлагается упрощенная модель передачи новых функций линейным руководителям. Использование таких рекомендаций может привести к негативным эффектам, связанным с разрозненностью моделей управления в отдельных функциональных блоках, увеличением нагрузки на линейных руководителей и невыполнение в полном объеме (до игнорирования) ими поставленных задач как второстепенных.

Управление трудом представляет собой систему с совокупностью свойств, присущих любой системе - в первую очередь, стремления к поддержанию жизненности, самоорганизации и саморазвития. Системообразующим блоком в управлении трудом являются разделение и кооперация труда и перемена труда. Развитие системы управления 
трудом в направлении упрочнения еe жизненности сопровождается усложнением структуры трудовых отношений. Эффективность управления трудом будет зависеть от того, насколько быстро система управления трудом может адаптироваться к этим социально-экономическим трансформациям. Сегодня в Республике Беларусь происходят изменения, касающиеся структуры экономики, социально-классовой дифференциации белорусского общества, становления и развития институциональной системы. Эти трансформации, с одной стороны, влияют на изменения в трудовых отношениях, a, с другой - обусловлены ими. В этой связи актуализируется вопрос, поставленный А.И. Татаркиным: «как построить организацию, в которой встроенные механизмы саморазвития позволяют реализовать свойства опережающей адаптации к изменениям внешней и внутренней среды?» [44, с. 114-115]. На практике зачастую изменения наталкиваются на препятствия, связанные с консерватизмом внутри предприятия и стремлением к самосохранению, т.е. сопротивлению к переходу в новое состояние или свойству диссипативности. Субъекты управления трудом делятся на тех, кто готов генерировать идеи и внедрять инновации; тех, кто активно сопротивляется переменам; третью группу составляют те, кто никак не выражает свою позицию. Соотношение указанных категорий должно быть детерминировано стратегией предприятия, которая может быть направлена на инновационное развитие либо на сохранение достигнутых конкурентных преимуществ. Спецификой труда в текстильной и швейной промышленности является его во многом творческий характер. Учет этого фактора проявляется в гибкости в принятии решений, наделении сотрудников правом на ошибку, делегировании полномочий на низшие звенья, большей степенью свободы в процессе труда. С другой стороны, это должно компенсироваться ростом требований к результатам труда, расширением границ ответственности, скоростью принятия решений, повышением требований к качеству человеческого капитала, усложнением функций. Исследования показывают, что трудовые ресурсы готовы воспринять эти требования: «происходит смена психологическои установки работников, повышается личная ответственность за выбор перспектив, работники принимают на себя карьерные риски и обеспечение своеи экономическои безопасности» [45, с. 67]. Отсутствие учета этих факторов на многих белорусских предприятиях текстильной и, в особенности, швейной промышленности привело к проблеме привлечения дизайнеров, художников-модельеров, конструкторов. Это обусловлено не отсутствием кадров необходимых компетенций и творческих способностей на рынке труда, а, в первую очередь, неэффективностью механизмов привлечения и удержания их на предприятиях. Предприятия текстильной швейной промышленности по-прежнему рассматривают человеческий ресурс как 
издержки, что подтверждается сокращением расходов на оплату труда в условиях кризиса и сохраняющаяся неоптимизированная структура занятости. Максимальное использование человеческого капитала без инвестирования в него приводит к его истощению и неэффективности в долгосрочной перспективе.

Таким образом, под управлением трудом в текстильной и швейной промышленности будем понимать комплекс организационных и институциональных инструментов, используемых для регулирования воспроизводства и распределения трудовых ресурсов в текстильной и швейной промышленности с целью реализации экономических и социальных интересов субъектов управления трудом (работников, собственников, инвесторов, производственных коллективов, топменеджеров, государства и т.д.). Функциональным назначением управления трудом в текстильной и швейной промышленности является обеспечение отрасли трудовыми ресурсами требуемой структуры для удовлетворения потребностей народного хозяйства и населения в продукции отрасли и технико-технологическое, функциональное и профессионально-квалификационное разделение труда, позволяющее эффективно реализовывать трудовой потенциал отрасли. Реализация трудового потенциала отрасли достигается через создание механизмов мотивации заинтересованных субъектов. На основе этого определено, что цель управления предприятием и цель управления трудом может совпадать частично.

В современной мировой текстильной и швейной промышленности существуют два идеальных (условных) типа развития - азиатская и европейская модель. Азиатская модель предполагает производство изделий по образцу дорогих брендов, используя свое сырье и технологии. Европейская модель характеризуется более длительным циклом создания изделия, который включает в себя разработку коллекций, работу на выставках и неделях моды, прием и размещение заказов на изготовление продукции, дистрибьюцию. Европейская модель, в отличие от азиатской, нацелена на создание относительно уникального продукта с высокой долей добавленной стоимости, обладающего высокими качественными характеристиками. Азиатская модель применяется в странах с низкой стоимостью рабочей силы, европейская в большей степени зависит от человеческого капитала (в первую очередь, творческой составляющей) отрасли. В Республике Беларусь, несмотря на низкую стоимость рабочей силы, не может быть сформирован рынок труда, позволяющий пойти по азиатскому пути развития. Вместе с тем отсутствие расширенного воспроизводства человеческого капитала отрасли пока не позволяет пойти отрасли по европейскому пути развития. 
Белорусская текстильная и швейная промышленность находится под влиянием двух групп факторов, которые необходимо учитывать в построении стратегии отрасли. Первая группа факторов, таких как создание зоны свободной торговли с Вьетнамом - одним из крупнейших мировых производителей продукции швейной промышленности [46]; поступательное снижение ставок ввозных таможенных пошлин в Таможенном союзе; ужесточение требований к производимой продукции по качеству и ассортименту; относительно низкая привлекательность отрасли для наиболее необходимых сегодня факторов производства - инвестиций и рабочей силы, могут привести к снижению спроса на продукцию текстильной и швейной промышленности, росту себестоимости производимой продукции, проблеме расширенного воспроизводства основных производственных факторов.

Вторая группа факторов будет способствовать росту доли добавленной стоимости на одного работника, снижению стоимости конечного продукта за счет экономии трансакционных издержек, внедрению новых технологий и моделей ведения бизнеса, позволяющих отрасли адаптироваться к новым условиям мировой экономической системы. Среди таких факторов можно выделить государственную поддержку по модернизации производств; доступ к административному ресурсу для выхода на новые внешние рынки сбыта через создание кластеров, поддержку концерна «Беллегпром»; развитие интермодальных транспортных технологий в Республике Беларусь (подробнее в [47]); участие китайского капитала в модернизации Оршанского льнокомбината, который является ядром кластера белорусской льноотрасли. В этой связи возникает ряд преимуществ, таких как налаживание каналов сотрудничества с поставщиками ресурсов, доступ к технологическим приемам, рост конкурентоспособности важнейшего участника кластера, что в случае согласования интересов субъектов - других участников кластера, принесет конкурентные преимущества не только для субъектабенефициара инвестиций, но и для других субъектов, объединенных с ним экономическими и социальными связями и отношениями.

\section{ВЫВОДЫ}

Для развития белорусской текстильной и швейной промышленности необходимо выработать собственную модель, основанную на рациональном использовании человеческого капитала; бережном отношении к трудовым ресурсам; усилению внутриотраслевого и внутрирегионального сотрудничества; сохранении стабильных производств, работающих по государственным заказам и с использованием давальческого сырья как гаранта сохранения рабочих мест и оборотных 
средств в кризисное время; инвестициях в инновационное производство продукции с высокой долей добавленной стоимости; высокой долей использования местных источников сырья, что снизит издержки на производство продукции и позволит использовать слабый белорусский рубль как преимущество. В инвестировании отрасли внимание должно быть сконцентрировано на тех ресурсах, которые дадут долговременную устойчивую отдачу. Выработка и переход к такой модели развития может быть осуществлен только при наличии профессиональных и мотивированных субъектов управления трудом.

\section{ЛИТЕРАТУРА}

1. Солодовников С. Ю. Тенденции и перспективы развития занятости и создания научного сообщества в условиях модернизации транзитивной экономики: на примере Республики Беларусь / С. Ю. Солодовников // Вестник Полоцкого государственного университета. Серия D: Экономические и юридические науки, 2015. № 6. - С. 2-9.

2. Абдурахманов К. Х. Управление трудовым потенциалом региона. — Ташкент : Узбекистан, 1990. - $173 \mathrm{c.}$

3. Буланов В. С. Основы социально-экономической теории развития человека / В. С. Буланов. - Москва : Проспект, 2014. — 204 с.

4. Волохин И.С. Трудовой потенциал Таджикистана и пути повышения эффективности его использования / И. С. Волохин. Душанбе, 1983.

5. Дегтярь Л. С. Трудовой потенциал общества и социальная политика: Из опыта европ. стран-членов СЭВ / Отв. ред. К. И. Микульский. - М : Наука, 1984. - 159 с.

6. Кунельский Л. Трудовой потенциал страны и повышение эффективности его использования / Л. Кунельский // Коммунист. 1984 № 14. - C. 27.

7. Костаков В. Интенсификация использования трудового потенциала / В. Костаков, А. Попов // Социалистический труд. 1982 № 7. - C. 61 .

8. Лутохина Э. А. Рынок труда в условиях глобализации / Э. А. Лутохина. - Минск : Академия управления при Президенте Республики Беларусь, 2015. - 178 с.

9. Маслова И. С. Трудовой потенциал советского общества: вопросы теории и методологии исследования. Москва : Политиздат, 1987. - 125 c. 
10. Социальная политика в сфере трудовых отношений / А.П.Морова; [Под науч. ред. П.Г.Никитенко]; Ин-т соц.-полит. исслед. при Администрации Президента Респ. Беларусь (ИСПИ). - Мн. : ИСПИ, 2000. - $174 \mathrm{c}$.

11. Одегов Ю. Г. Управление трудовым потенциалом промышленных предприятий в условиях НТП / Автореф. дисс. на соиск. ученой степени доктора эконом. наук // М. : Моск. ин-т нар. хоз-ва им. Г.В. Плеханова. - 1988. - 38 с.

12. Павлов Я. А. Трудовой потенциал работника / Я. А. Павлов. Кишинев : Штиинца, 1977. - 64 с.

13. Психомахов Х. М. Расширенное воспроизводство трудового потенциала как условие устойчивого развития региона / Автореф. дисс. на соиск. ученой степени доктора эконом. наук. - Москва, 2005. - 45 с.

14. Сергеева Г. П. Трудовой потенциал страны / Г. П. Сергеева, Л. С. Чижова // М.: Знание, 1982. - 64 с.

15. Хадасевич Н. Р. Трудовой потенциал в системе экономических отношений / Уровень жизни населения регионов России. 2015. № 1 (195). - С. 112-119.

16. Шаталова Н. И. Трудовой потенциал работника. - М. : ЮНИТИ, 2003. - 398 с.

17. Шевченко С. В. Оценка эффективности использования трудового потенциала / С. В. Шевченко // Труды БГТУ. Экономика и управление. 2014. - № 7. - С. 25-29.

18. Экономика труда : Учебник / Под ред. проф. П.Э. Шлендера и проф. Ю.П. Кокина. - М.: Юристь, 2003. - 592 с.

19. Васюченок Л. П. Некоторые мифы о соотношении производительности труда и заработной платы в белорусской экономике // Л. П. Васюченок / Экономическая наука сегодня . - Выпуск 4. - Минск, БНТУ, 2016. - С. 5-10.

20. Солодовников С. Ю. Социальный капитал как фактор экономического роста / С.Ю. Солодовников // Экономика и банки. 2015. № 1. - C. 32-41.

21. Солодовников С. Ю. Социально-экономические условия перехода Республики Беларусь к постиндустриальному обществу / С. Ю. Солодовников // Известия Самарского научного центра Российской академии наук. — 2007. - Т. 9. — № 2. С. 443-448.

22. Антосенков Е. Г. Текучесть кадров в промышленности и пути ее сокращения. - [Барнаул] : Алт. кн. изд-во, 1971. — 206 с.

23. Хрищев Е. И., Трудовая инициатива и ее стимулирование / Е. И. Хрищев, Л.С. Бляхман. - Кишинев : Картя молодовеняскэ, 1981. - $143 \mathrm{c}$. 
24. Волгин А. И. Эффективность общественного производства и трудовые ресурсы. - М. : Изд-во стандартов, 1980. - 112 с.

25. Локтев В.П. Экономические рычаги управления в условиях развитого социализма. - Мн. : Беларусь, 1976. - 93 с.

26. Погосян Г. Р. Материальное стимулирование в подрядных бригадах. - Ереван : Айастан, 1984. - 173 с.

27. Тейлор Ф. Принципы научного менеджмента / Пер. с англ. А.И. Зак. - М. : Журнал «Контроллин», 1991. — 104 с.

28. Херцберг Ф. Мотивация к работе / Ф. Херцберг, Б. Моснер, Б. Снидерман. - Москва; Санкт-Петербург : Вершина, 2007. - 238 с.

29. Адамчук В. В. Хозяйственный механизм управления трудовыми ресурсами. — М. : МИУ, 1981. —47 с.

30. Система управления трудом в развитом социалистическом обществе / [Б. М. Сухаревский, Л.А. Костин, А.В. Батурин и др.]. 2-е изд., перераб. и доп. - М. : Экономика, 1983. - 583 с.

31. Рофе А. И. Экономика труда / А.И. Рофе, В.Т. Стрейко, Б.Г. Збышко. — М. : МИК, 2000. — 247 с.

32. Оценка экономической и социальной эффективности управления персоналом организации / Государственный университет управления. - Москва : Проспект, 2014 . - 40 с.

33. Трансформация системы управления человеческими ресурсами региона в условиях экономического кризиса : проблемы и тенденции / [М.А. Винокуров и др.]. - Иркутск : Издательство БГУЭП, 2010. - 359 с.

34. Корнеску В. И. Производительность труда и человеческий фактор. - М. : Экономика, 1979. - 156 с.

35. Саймон Г. Менеджмент в организациях : Сокр. пер. с англ. с 15-го изд. / Саймон, Г., Смитбург Д., Томпсон В. : Общ. ред. и вступ. ст. А.М. Емельянова и В.В. Петрова. - М. : Экономика, 1995. - 335 с.

36. Сотникова С. И. Управление карьерой / С.И. Сотникова. М. : Изд. дом «Инфра-М», 2001. - 407 с.

37. Прангишвили И.В. Энтропийные и другие системные закономерности / М. : Наука, 2003. - 426 с.

38. Хьюзлид М. А. Оценка персонала: как управлять человеческим капиталом, чтобы реализовать стратегию / М. А. Хьюзлид, Б. И. Беккер, Р. В. Битти. Пер. с англ. - М.: ООО «И.Д. Вильямс», 2007. - 432 с.

39. Herbst, P.G., «Problems of Theory and Method in the Integration of the Behavioural Sciences», Human Relations, November,. - 1965.

40. Джонсон Р. Системы и руководство / Р. Джонсон, Ф. Каст, Д. Розенцвейг // Перевод с англ. Михайлова И.М. [и др.] Под ред. [и с предисл.] Гаврилова Ю.В. и Печатникова Ю.Т. - Изд. 2-е, доп. - М. : Сов. радио, 1971. - 648 с. 
41. Коул Д. Управление персоналом в современных организациях / Джеральд Коул; [Пер. с англ. Н.Г. Владимирова]. - М.: ООО «Вершина», 2004. $-352 \mathrm{c}$.

42. Молодчик А. В, Менеджмент: стратегия, структура, персонал, знание / А.В. Молодчик, М.А. Молодчик. - Москва : Издательский дом НУ ВШЭ, 2005. - $296 \mathrm{c.}$

43. Монди, У. Р. Управление персоналом / У. Р. Монди, Р. М. Ноу, Ш. Р. Премо // Пер. с англ. под ред. И.В. Андреевой, С.В. Кошелевой. СПб.: Издательский Дом «Нева», 2004. - 640 с.

44. Саморазвивающиеся социально-экономические системы: теория, методология, прогнозные оценки : в 2 т. / Рос. акад. наук, Урал. отд-ние, под общ. ред. А.И. Татаркина. - Москва : ЗАО «Издательство «Экономика»; Екатеринбург: УрО РАН, 2011. - Т.1: Теория и методология формирования саморазвивающихся социально-экономических систем. -308 с.

45. Солодовников С.Ю. Общее и особенное в развитии занятости в Республике Беларусь и в Украине / С.Ю. Солодовников, Т.В. Кузьмицкая, О.Р. Кривицкая // Наукові записки Національного університету «Острозька академія». Серія «Економіка»: збірник наукових праць / ред. кол.: I. Д. Пасічник, О. І. Дем'янчук. - Острог : Видавництво Національного університету «Острозька академія», 2013. - Випуск 24. - С. 64 - 70.

46. Евразийская экономическая комиссия [Электронный ресурс]. Режим доступа: http://www.eurasiancommission.org/ru/act/trade/ dotp/sogl torg/Documents/Обзор\%20Соглашения $\% 20$ о\% 20 свободной\%20торговле\% $\%$ 0между\%20странами\%20ЕАЭС\%20и\%20Вьетнамом.pdf. - Дата доступа: 01.08.2016.

47. Солодовников С. Ю. Развитие интермодальных транспортных технологий в интересах Республики Беларусь и стран-соседей / С. Ю. Солодовников, О. М. Мазуренко, Ю. В. Мелешко // Научнообразовательный центр «Технологии товароведческой, таможенной и криминалистической экспертизы» : сборник научных работ / под ред. Г. Д. Дроздова. - СПб.: Изд-во СПбГЭУ, 2015. - С. 156-158.

Статья поступила в редакиию 10 декабря 2016 года. 